\title{
Adsorptive characteristics and microwave dielectric properties of oil palm empty fruit bunch-based activated carbons for dye removal
}

\author{
Muhammad Abbas Ahmad Zaini a, b, ${ }^{*}$, Abdul Haris Ali a, b \\ a Centre of Lipids Engineering \& Applied Research, Ibnu-Sina Institute for Scientific \& Industrial Research, Universiti Teknologi Malaysia, 81310 \\ UTM Johor Bahru, Johor, Malaysia \\ ${ }^{b}$ Department of Chemical Engineering, Faculty of Chemical \& Energy Engineering, Universiti Teknologi Malaysia, 81310 UTM Johor Bahru, Johor, \\ Malaysia \\ * Corresponding author: abbas@cheme.utm.my
}

\section{Article history}

Received 15 January 2018

Revised 1 April 2018

Accepted 15 May 2018

Published Online 4 June 2018

\section{Graphical abstract}

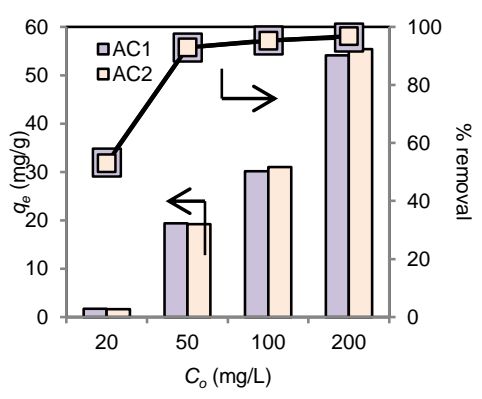

\begin{abstract}
The present study was aimed to evaluate the adsorptive characteristics and microwave dielectric properties of activated carbons derived from oil palm empty fruit bunch (EFB) prepared by microwave-assisted potassium hydroxide activation at $300 \mathrm{~W}$ and $800 \mathrm{~W}$ for $5 \mathrm{~min}$. The resultant products were characterized for dielectric properties, BET specific surface area, surface functional groups and methylene blue adsorption. Results show that the microwave-assisted activation yields activated carbons with surface area of $695 \mathrm{~m}^{2} / \mathrm{g}$ and $1339 \mathrm{~m}^{2} / \mathrm{g}$ for heating rates (microwave irradiation power) of $300 \mathrm{~W}$ and $800 \mathrm{~W}$, respectively and both exhibit more than $95 \%$ removal of methylene blue at concentrations higher than $100 \mathrm{mg} / \mathrm{L}$. The dielectric properties revealed a better propensity of activated carbons towards microwave heating especially at a higher heating rate due to high surface area, and possibly high moisture content and carbon content. A greater heating rate or microwave power could turn EFB into activated carbon with a higher surface area and excellent adsorptive properties for pollution abatement.
\end{abstract}

Keywords: Activated carbon, dielectric properties, dye adsorption, microwave heating, moisture content, penetration depth

(C) 2018 Penerbit UTM Press. All rights reserved

\section{INTRODUCTION}

There has been an increasing interest in the preparation of activated carbon using renewable and cheaper precursor as to compensate the high price of commercial activated carbon. In general, the agricultural wastes are perceived as the important raw material of activated carbon due to high carbon content, abundantly available, sustainable supply and cheap (Saygili et al., 2015). A number of successful attempts to produce activated carbons from agro-wastes such as date stones (Abbas \& Ahmed, 2016), date pits (Mahmoudi et al., 2014), langsat empty fruit bunch (Foo \& Hameed, 2012a; Njoku et al., 2015), oil palm empty fruit bunch (Zaini \& Shaid, 2016), pineapple peel (Foo \& Hameed, 2012b), rice husks (Foo \& Hameed, 2011a), sunflower seeds oil residue (Foo \& Hameed, 2011b) and durian shells (Foo \& Hameed, 2012c) have been documented in literature. The strategy to utilize the wastes as the feedstock assists in reducing the costs of waste handling and disposal, and further provides a solution to the environmental problems (Saygili et al., 2015).

The preparation of activated carbon involves two steps, i.e., carbonization and activation. Carbonization aims to enrich the carbon content in order to create rudimentary pores as a result from the release of volatiles in char, while activation helps to develop the pore textures of activated carbon. The raw material conversion into activated carbon can be done through physical activation or chemical activation. In physical activation, the char is reacted with oxidizing gases such as $\mathrm{CO}_{2}$ and/or steam at temperatures between $700^{\circ} \mathrm{C}$ and $1000^{\circ} \mathrm{C}$ (Zaini et al., 2010). Chemical activation, on the other hand utilizes chemical reagent such as $\mathrm{KOH}, \mathrm{ZnCl}_{2}$ or $\mathrm{H}_{3} \mathrm{PO}_{4}$ that acts as dehydrating agent to promote pyrolytic decomposition and inhibit the formation of tar (Zaini et al., 2009; Saygili et al., 2015). The carbonization step can be skipped in chemical activation, as the impregnated-precursor is readily viable for activation. Chemical activation is more preferred over physical activation due to the fact that the former can be done at a lower temperature $\left(400^{\circ} \mathrm{C}\right.$ to $\left.600^{\circ} \mathrm{C}\right)$ with a higher yield of activated carbon (Zaini et al., 2009; Zaini et al., 2013).

It is widely accepted that the use of conventional heating using furnace for activation is time-consuming and energy-intensive. Recent development in activated carbon preparation demonstrated the feasibility of using microwave in assisting the chemical activation (Foo \& Hameed, 2011a-b; Foo \& Hameed, 2012a-c) . Interestingly, the physicochemical properties of activated carbons produced are similar to that obtained using conventional heating. Compared to conventional heating, microwave heating offers rapid volumetric and selective heating, high heating rates and product yield, and small equipment size and wastes released (Zaini \& Kamaruddin, 2013). However, much of available published studies focusing only on the microwave-assisted production of activated carbons from various raw materials with lack of attention on the effect of heating rate, and the fundamentals of dielectric properties.

The dielectric properties (or permittivity, $\varepsilon^{*}$ ) is expressed as,

$$
\varepsilon^{*}=\varepsilon^{\prime}-j \varepsilon^{\prime}
$$


where $\varepsilon^{\prime}$ is the dielectric constant (real part of permittivity), that is a measure of how much energy from an external electric field is stored within a material through polarization mechanism, while $\varepsilon$ " is the loss factor (imaginary part of permittivity) that represents the ability of material to absorb and dissipate the electromagnetic energy into heat. The loss tangent $(\tan \delta$ ) is used to describe how efficient the electromagnetic energy stored within a material is converted into heat at a specific frequency and temperature. It is given as,

$$
\tan \delta=\varepsilon " / \varepsilon,
$$

The dielectric properties aid in scrutinizing microwave heating and material interaction, predicting the heating rates, and describing the heating characteristics and behaviour of a material when subjected to a high-frequency electromagnetic field (Zaini \& Kamaruddin, 2013). Penetration depth, $D_{\mathrm{P}}$ is used to determine how far the electromagnetic power can go inside a material, and it is given as,

$$
D_{P}=\frac{\lambda_{o} \sqrt{\varepsilon^{\prime}}}{2 \pi \varepsilon^{\prime \prime}}
$$

where $\lambda_{o}$ is the free space microwave wavelength (for $2.45 \mathrm{GHz}, \lambda_{o}=$ $12.2 \mathrm{~cm}$ ). The volumetric heating of microwave could be less operative for a material with short penetration depth when only small portion of material thickness absorbs the microwaves. Consequently, the heating would not be uniform due to poor strength of electromagnetic wave at the material core that farther the penetration depth (Zaini \& Kamaruddin, 2013; Alias \& Zaini, 2015).

The dielectric properties of impregnated agro-wastes such as $\mathrm{K}_{2} \mathrm{CO}_{3}$-impregnated cempedak peel (Alias et al., 2017a), NaOHimpregnated cempedak peel (Alias et al., 2017b), KOH-impregnated palm kernel shell (Zaini et al., 2015a), and $\mathrm{ZnCl}_{2}$-impregnated palm kernel shell (Zaini et al., 2015b) at different concentrations depicted a promising role of activating agents as microwave absorber in chemical activation. However, the interaction between heating rate (or microwave power) and dielectric properties of activated carbons is not well understood, and has to be established to enrich the present literature. Therefore, the objective of the present work is to evaluate the dielectric properties of empty fruit bunch-based activated carbons prepared using microwave power of $300 \mathrm{~W}$ and $800 \mathrm{~W}$. Potassium hydroxide was used as the activating agent, while methylene blue dye was used to probe the performance of activated carbons. The changes and relationships between the activated carbons characteristics and dielectric properties were discussed to shed some light on factors that can provide positive effects in microwave-assisted activation at varying heating rates.

\section{EXPERIMENTAL}

\section{Materials}

Empty fruit bunch was obtained from Kluang plantation at Johor state of Malaysia. Methylene blue dye (molecular weight $=319.85$ $\mathrm{g} / \mathrm{mol}$ ) was purchased from $\mathrm{HmbG}$ Chemicals. Potassium hydroxide was supplied by QRec. All chemicals are of analytical-grade reagents.

\section{Microwave-assisted activation}

Oil palm empty fruit bunch (EFB) was ground to an average size of $1 \mathrm{~mm}$. EFB was impregnated with potassium hydroxide $(\mathrm{KOH})$ at a solid weight ratio (KOH : EFB) of 1.5:1. The desired weight of $\mathrm{KOH}$ pellets was dissolved in distilled water, and then mixed with the desired weight of dried EFB. The mixture was homogeneously stirred and heated for $30 \mathrm{~min}$, and then dried in an oven at $110^{\circ} \mathrm{C}$ for $24 \mathrm{~h}$. Five grams of impregnated sample was placed in a crucible inside a Teflon container. The cap of the container was tightened, and the container was put in a microwave chamber. An exhaust tube was connected from the Teflon cap through the microwave cavity and directly to the fume hood. The microwave-assisted activation was performed using a $2.45 \mathrm{GHz}$ multimode microwave applicator (Samsung Me711K), at microwave heating rates of $300 \mathrm{~W}$ and $800 \mathrm{~W}$ for $5 \mathrm{~min}$. The resultant activated carbons were washed with distilled water and dried in an oven at $110^{\circ} \mathrm{C}$ for $24 \mathrm{~h}$ prior to use. The activated carbons were labelled as $\mathrm{AC} 1$ and $\mathrm{AC} 2$, respectively. EFBbased char was also prepared for comparison by conventional heating, at $500^{\circ} \mathrm{C}$ for $2 \mathrm{~h}$ in a muffle furnace.

\section{Characterization of activated carbons}

A Fourier transform infrared spectroscopy combined with attenuated total reflectance (IRTracer-100, Shimadzu) was used to determine the surface functional groups of EFB-derived materials. The specific surface area of activated carbons were determined using a Pulse ChemiSorb 2705 (Micrometrics) at a liquid $\mathrm{N}_{2}$ temperature of $77 \mathrm{~K}$. The surface area was calculated using a single-point BrunauerEmmett-Teller (BET) method.

The dielectric properties of EFB and its derived samples were measured at various microwave frequencies $(1-6 \mathrm{GHz})$ using an open-ended coaxial probe technique. The measurement system consists of a coaxial probe (HP 85070D) attached to a Vector Network Analyzer (VNA model HP 8720B). The measurement of each sample was repeated at least three times to ensure good reproducibility of data.

\section{Adsorption of methylene blue}

The adsorption of methylene blue onto EFB-based activated carbons and char was performed using a bottle-point technique. The initial $\mathrm{pH}$ of methylene blue solution was not adjusted, and was measured as $5.9 \pm 0.2$. Thirty $\mathrm{mg}$ of activated carbon was brought into intimate contact with $30 \mathrm{~mL}$ of methylene blue solution of different concentrations $(1-200 \mathrm{mg} / \mathrm{L})$. Next, the solution mixture was allowed to equilibrate for $72 \mathrm{~h}$. After that, the residual concentration was measured using a visible spectrophotometer (Halo Vis-10) at a wavelength of $615 \mathrm{~nm}$. The adsorption capacity, $q_{e}(\mathrm{mg} / \mathrm{g})$ was calculated as, $q_{e}=\left(C_{o}-C_{e}\right) \times V / m$, where $C_{o}$ and $C_{e}(\mathrm{mg} / \mathrm{L})$ are the initial and equilibrium concentrations, respectively, $V(\mathrm{~L})$ is the volume of methylene blue solution, and $m(\mathrm{~g})$ is the weight of char.

\section{RESULTS AND DISCUSSION}

\section{Characteristics of activated carbons}

Table 1 shows the yield and BET surface area of EFB-based char and activated carbons. The carbonization (to produce char) and microwave-assisted activation processes have resulted in the decrease of yield. The yield of char is $75 \%$, while that of activated carbons are $67 \%$ and $61 \%$, respectively. The weight loss during material heating either by means of conventional heating or microwave is generally due to the release of volatile products with the increase of temperature, and this becomes more intensified under the presence of dehydrating agent (potassium hydroxide) which accelerates the elimination reaction and gasification of surface carbon. The decrease of yield in microwave-assisted potassium hydroxide activation is more pronounced at a higher microwave power of $800 \mathrm{~W}$. This could be resulted from a greater heating rate as the microwave power increases which also infers that the activation was held at a higher temperature for the same 5 min retention.

Table 1 Yield and BET surface area of EFB-derived char and activated carbons.

\begin{tabular}{cccc}
\hline Sample & Yield $(\%)$ & $\mathbf{p H}$ & Surface area $\left(\mathbf{m}^{2} / \mathbf{g}\right)$ \\
\hline EFB & 100 & 7.8 & 28 \\
Char & 74.7 & 6.8 & 37 \\
AC1 & 66.9 & 8.1 & 695 \\
AC2 & 60.6 & 7.8 & 1339 \\
\hline
\end{tabular}

From Table 1, the order of specific surface area is, EFB < char $<$ $\mathrm{AC} 1<\mathrm{AC} 2$. The surface area of char upon carbonization slightly increases due to the initiation of rudimentary pores. AC2 exhibits a higher surface area than $\mathrm{AC} 1$ as the heating rate enhances the development of new pores and active sites, hence increasing the pore volume and surface area at a higher temperature. The combined effect of volumetric and internal heating of microwave accelerates the 
activation process in a rapid manner (5 min) (Hesas et al., 2013). Generally, the specific surface area of $\mathrm{AC} 1$ and $\mathrm{AC} 2$ are within the acceptable range of commercial activated carbon (Hidayu et al., 2013). AC2 demonstrates a greater surface area than $\mathrm{ZnCl}_{2}$-activated EFB carbon (surface area of $866 \mathrm{~m}^{2} / \mathrm{g}$ ) prepared by conventional heating (Zaini \& Shaid, 2016). In addition, the surface area of AC2 is comparable with that of other $\mathrm{KOH}$-activated carbons prepared via conventional heating, but the ones produced through microwaveassisted activation as demonstrated in this work, offers a far better yield in a very short time (Shu Hui \& Zaini, 2015).

Attempt has been made in this work to activate EFB under irradiated water environment at $800 \mathrm{~W}$. The underlying theory of irradiated water was introduced in the previous works (Zaini et al., 2014a-b). The mixture of EFB and $\mathrm{KOH}$ solution was added into an uncapped Beatson bottle inside a Teflon container. The subsequent activation procedures are the same as described earlier. After 5 min activation, the solution was partly dried, while the EFB still retained its light brown colour. Surprisingly, no value of surface area was recorded by the resultant product. It is suggested that the available pores of the pristine EFB are clogged by potassium salt during the microwave-drying, thus decreasing the surface area from $28 \mathrm{~m}^{2} / \mathrm{g}$ to null (Zaini \& Shaid, 2016). Furthermore, the role of irradiated water, with or without the presence of dehydrating agent, that was claimed to mimic that of steam activation could not be well justified. It is of common knowledge that water is an excellent microwave absorber that can turn microwaves into heat (Zaini et al., 2015c). However, the heat that is propagated during the irradiation process (microwave drying) may not exceed the water boiling point $\left(100^{\circ} \mathrm{C}\right)$. The so-called 'irradiated water environment' can only be made possible if the $\mathrm{KOH}$ solution bearing EFB is completely dried and sufficient time is allowed for the intercalation of potassium cations within the EFB matrix to create new pathways for the porous structure under the presence of microwaves (Zaini et al., 2014c). In fact, the activation process is promoted due to the formation of microplasmas and hot spots on the dried solids surface that can reach up to several hundreds and thousands degree centigrade (Alias \& Zaini, 2015; Zaini et al., 2015c).

Fig. 1 shows the FTIR spectra of EFB, char, AC1 and AC2. The EFB spectrum exhibits several peaks located at $3310 \mathrm{~cm}^{-1}, 2920 \mathrm{~cm}^{-1}$, $1610 \mathrm{~cm}^{-1}$ and $1040 \mathrm{~cm}^{-1}$, that correspond to the characteristics of $\mathrm{O}$ $\mathrm{H}$ (hydroxyl), $-\mathrm{CH}_{2}$ (alkyl), $\mathrm{C}-\mathrm{O}-\mathrm{C}$ (ester, ether and phenol) and $\mathrm{C}-\mathrm{O}$ (anhydrides). Three major functional groups in EFB are hydroxyl groups, carbonyl groups and carboxyl groups [14]. On the other hand, the char spectrum displays a peak with weak band at $3117 \mathrm{~cm}^{-1}$ which is attributed to $-\mathrm{CH}_{2}$ (alkyl). A number of peaks formerly seen in EFB spectrum are disappeared due to the elimination of volatiles and heatsensitive functional groups at $500^{\circ} \mathrm{C}$ (Zaini et al., 2016).

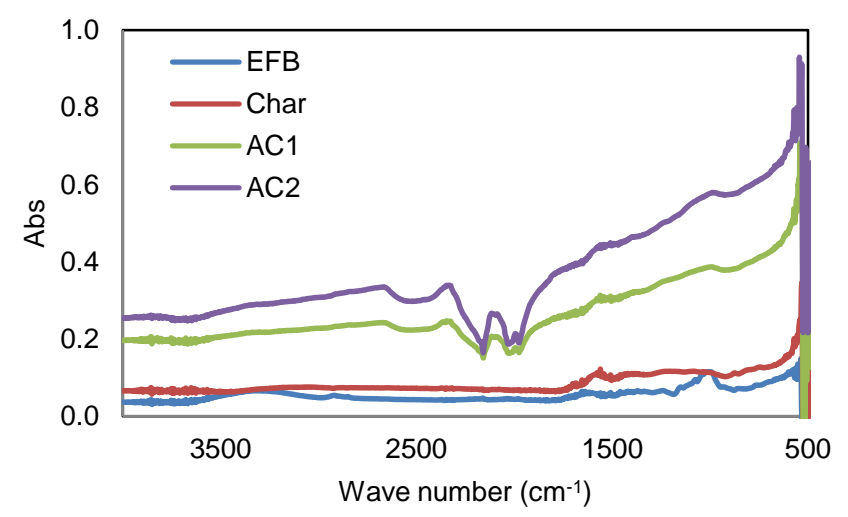

Fig. 1 FTIR spectra of EFB, char, AC1 and AC2.

From Fig. 1, AC1 and AC2 display similar FTIR spectra, indicating identical quality of surface functional groups. The absorption bands at $2660 \mathrm{~cm}^{-1}$ and $2330 \mathrm{~cm}^{-1}, 1570 \mathrm{~cm}^{-1}$ and $980 \mathrm{~cm}^{-1}$ are the characteristics of $\mathrm{O}-\mathrm{H}$ (carboxylic acids), $\mathrm{C}-\mathrm{H}$ (alkyls) and $\mathrm{C}-\mathrm{O}$ (anhydrides), respectively. Yet, AC2 exhibits peaks with greater intensity as compared to $\mathrm{AC} 1$, which also suggests a greater quantity of functional groups in AC2.

\section{Dielectric properties and penetration depth of activated carbons}

Fig. 2 shows the profiles of dielectric properties of EFB, char, $\mathrm{AC} 1$ and $\mathrm{AC} 2$ at different microwave frequencies.
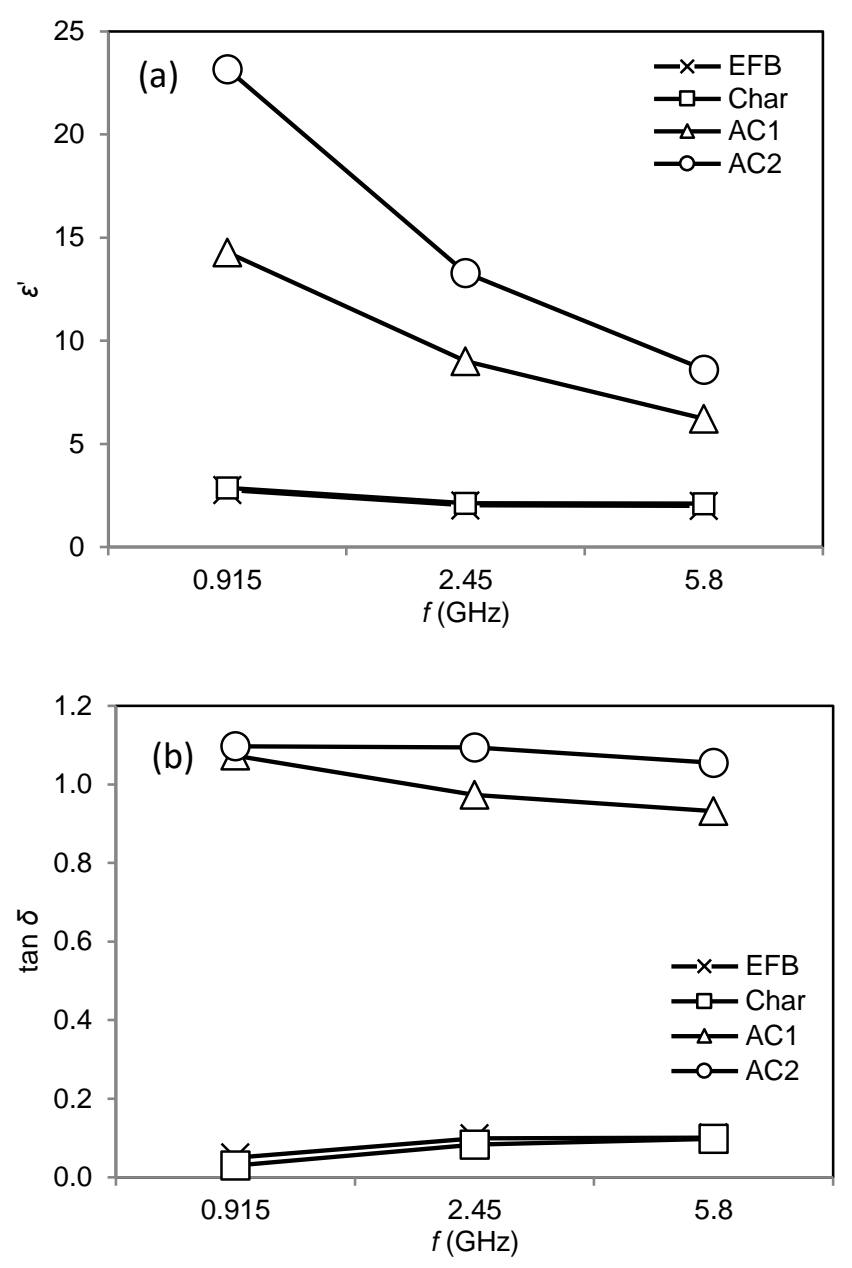

Fig. 2 Profiles of dielectric properties of EFB and its derived materials (a) dielectric constant, and (b) loss tangent.

From Fig. 2(a), AC2 displays a higher dielectric constant $\left(\varepsilon^{\prime}\right)$, followed by AC1, char and EFB, where the profiles of EFB and char are fairly overlapped. This pattern is true with the increase of microwave frequencies. Also, for all materials studied, the $\varepsilon^{\prime}$ decreased with increasing frequency as a result of polarization effect due to varying electric field (Salema et al., 2013). The presence of moisture in $\mathrm{AC} 1$ and $\mathrm{AC} 2$ could be the main reason for a higher $\varepsilon^{\prime}$ at any frequency despite the rapidly diminished conductive effect of microwave heating (Alias \& Zaini, 2015). AC1 and AC2 possess a higher surface area compared to char and EFB. A greater surface area as a result of a higher heating rate of microwave-assisted $\mathrm{KOH}$ activation also implies a larger pore volume to accommodate naturally physisorbed water from the surrounding. The moisture content offers the flexibility of the free ions in the material to move and contribute to high loss $(\tan \delta$ ) or conductivity loss (Omar et al., 2011). Other factors such as ash content, carbon content and functional groups could also offer positive effects on $\varepsilon^{\prime}$ (Alias \& Zaini, 2015; Alias et al., 2017b). Hence, $\varepsilon^{\prime}$ is a complex function that varies especially when there is a change in the intrinsic properties of the material during microwave-assisted activation. The increase of carbon content in the form of graphitic structure upon activation indeed plays an important role in the dielectric properties (through orientation polarization) because of the presence of aromatic rings. The delocalized $\pi$-electrons can move freely in a broad region and might create ionization to the surrounding (Salema et al., 2013; Zaini \& Kamaruddin, 2013). On the contrary, the EFB-based char exhibits an 
inferior dielectric properties probably due to the under-developed graphitic structure even though the carbon content increased upon carbonization (Zaini et al., 2015c).

The profiles of loss tangent $(\tan \delta)$ are shown in Fig. 2(b). AC1 and $\mathrm{AC} 2$ exhibit higher values of $\tan \delta$ compared to char and $\mathrm{EFB}$, suggesting that they are more efficient to be heated under microwaves. In general, sample with high $\tan \delta$ normally has a better energy absorption properties, energy storage characteristic and a higher heating rate (Zaini et al., 2015a) . Also, it shows the underlying roles of $\mathrm{KOH}$ to promote surface area in EFB-based activated carbons, and inherent moisture content in enhancing the efficiency of microwave heating. Water is known as natural polar and prominent microwave absorber, and has been used as a benchmark for other dielectric materials (Sosa-Morales et al., 2010). However, the pattern of $\tan \delta$ for all samples are inconsistent with increasing frequency due to the decrease in interfacial polarization (Zaini et al., 2015a) and/or gradual decrease in the dipole movement that produces heat within the material via molecular polarization (Salema et al., 2013; Zaini et al., 2015b).

EFB can be heated under microwave but may not be as rapid as that of high loss material (absorber). However, once it is transformed into rich graphitic carbon structure (activated carbon), the $\tan \delta$ gets much higher. The EFB-based activated carbons are good microwave absorbers for microwave-assisted activation due to high values of tan $\delta(\tan \delta>0.1)$. On the other hand, EFB and char are classified under low microwave absorbing dielectric materials $(\tan \delta<0.1)$. Accordingly, these samples may not be suitable for microwaveassisted activation, unless an impedance matching (tuning) system between the load (sample) and microwave power source to ensure maximum transfer of power is installed (Zaini \& Kamaruddin, 2013). Consequently, the selection of microwave frequency for chemical activation should be carefully selected to improve the effectiveness of the activation process. As such, multiple adjustment of frequency during the course of activation can be proposed.

Fig. 3 shows the penetration depth of EFB, char, AC1 and AC2 at different microwave frequencies. Penetration depth, $D_{p}$ is defined as the depth into material where the power reduced to $\sim 1 / e$ of the original intensity, and can be used to evaluate the microwave heating uniformity. From Fig. 3, AC1 and AC2 show a smaller $D_{p}$ probably due to high moisture content that trapped within the pore textures. The microwave heating of the material with high moisture content may be localized only on the surface due to short $D_{p}$. This is where the hotspots are mainly centered in heating the moisture (Motasemi et al., 2014).

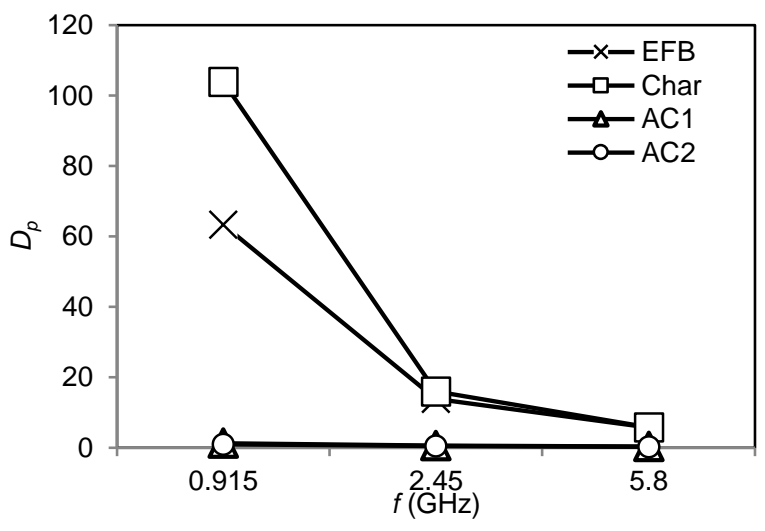

Fig. 3 Penetration depth of EFB and EFB-derived samples.

A non-uniform heating can also happen if the size of the sample to be heated is larger than the $D_{p}$ of the microwave. Homogenous heating may not take place as the energy is absorbed only near the surface of the material (Sait \& Salema, 2015). Nevertheless, the $D_{p}$ for AC1 and AC2 are longer than their particle size, which infers that the uniform heating can take place. On the other hand, a high $D_{p}$ as depicted by char indicates that the material is somewhat transparent to the microwaves with low or no microwave absorption. However, it enables even the thicker bed of char to be processed due to its high penetration depth. The penetration depth also provides the preliminary knowledge and understanding on the size of the target material in the manufacture of activated carbon using microwaves. It is shown in Fig. 3 that, with increasing frequency, the $D_{p}$ of all the samples decreases. This might be due to the difference of wavelength of the frequencies. For instance, a longer wavelength of $32.75 \mathrm{~cm}(0.912 \mathrm{GHz})$ penetrates more than a shorter wavelength of $12.24 \mathrm{~cm}(2.450 \mathrm{GHz}$ ) (Sait \& Salema, 2015).

\section{Methylene blue adsorption}

Fig. 4 represents the methylene blue removal by EFB-based materials. In general, the removal capacity of methylene blue increased with increasing concentration, indicating a favourable adsorption process. As the concentration increases, the driving force for the dye molecules to lodge on the pores and active sites also increases. AC1 and AC2 show a higher capacity of $1.6 \mathrm{mg} / \mathrm{g}$ than char that yields only $0.78 \mathrm{mg} / \mathrm{g}$ at $C_{o}=20 \mathrm{mg} / \mathrm{L}$. In addition, AC1 and AC2 display an increasing pattern of dye percentage removal with a comparable performance of $53 \%$ at $C_{o}=20 \mathrm{mg} / \mathrm{L}$. On the other hand, char recorded a higher performance of $35 \%$ at $C_{o}=10 \mathrm{mg} / \mathrm{L}$, after which the percentage removal began to drop, indicating the maximum capacity or saturation point has been reached.

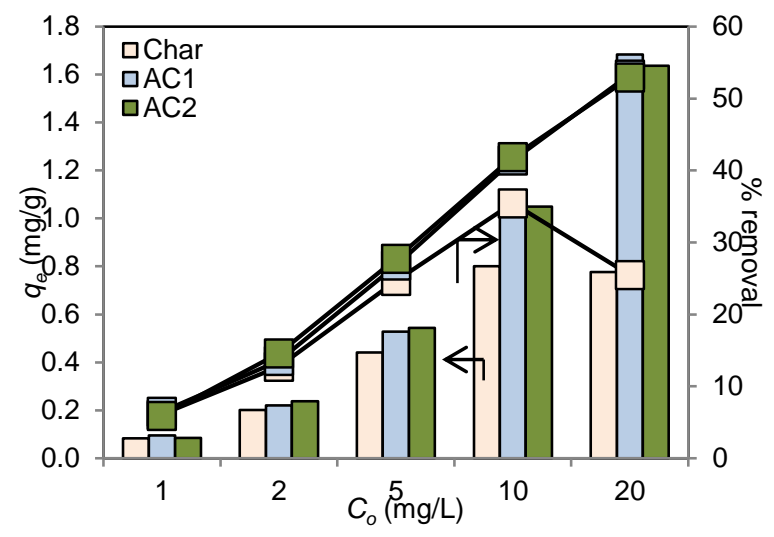

Fig. 4 Removal of methylene blue by EFB-based materials.

Fig. 5 shows the adsorption of methylene blue onto AC1 and AC2 at higher concentrations. AC1 and AC2 display a similar pattern of increasing adsorption capacity with increasing concentration. The adsorption capacity of $55 \mathrm{mg} / \mathrm{g}$ was recorded at $C_{o}=200 \mathrm{mg} / \mathrm{L}$. Furthermore, the percentage removal shows an exceptional increase of more than $95 \%$ at concentrations greater than $100 \mathrm{mg} / \mathrm{L}$. In an earlier work, Mohd.-Nasir et al. (2015) reported a maximum (saturation) capacity of $32 \mathrm{mg} / \mathrm{g}$ of methylene blue adsorption onto untreated EFB at $C_{o}=237 \mathrm{mg} / \mathrm{L}$, which accounts for $13.5 \%$ removal. It implies that the EFB-based activated carbons are promising adsorbent for dye adsorption as they can still accommodate more dye molecules beyond the concentrations studied.

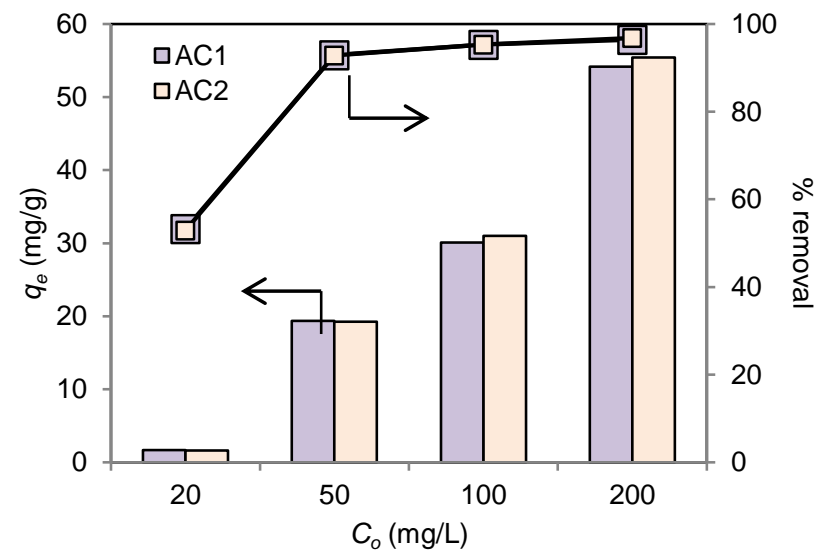

Fig. 5 Removal of methylene blue by EFB-based activated carbons at higher concentrations. 


\section{CONCLUSION}

Oil palm empty fruit bunch was converted into activated carbons by microwave-assisted $\mathrm{KOH}$ activation at heating rates (microwave irradiation power) of $300 \mathrm{~W}$ and $800 \mathrm{~W}$. Activation at $800 \mathrm{~W}$ produces activated carbon with $61 \%$ yield and a surface area of 1339 $\mathrm{m}^{2} / \mathrm{g}$. Activated carbons demonstrate higher dielectric constant and loss tangent due to their high surface area and possibly high moisture content, hence possess better propensity to be heated under microwaves. Nevertheless, an impedance matching system and multiple adjustment of frequency can be proposed in microwaveassisted activation to enable maximum transfer of power and uniformity of the heating process. Activated carbons produced in this work display a comparable performance of more than $95 \%$ dye removal at $C_{o}=200 \mathrm{mg} / \mathrm{L}$. It shows a promising application of EFBbased activated carbons prepared by microwave-assisted activation for dye removal from wastewater.

\section{ACKNOWLEDGEMENT}

This work was financially supported by Tier 1 Universiti Teknologi Malaysia-Research Universiti Grant \#18H50.

\section{REFERENCES}

Abbas, A. F., Ahmed, M. J. 2016. Mesoporous activated carbon from date stones (Phoenix dactylifera L.) by one-step microwave assisted $\mathrm{K}_{2} \mathrm{CO}_{3}$ pyrolysis. J. Water Proc. Eng. 9, 201-207.

Alias, N., Kamaruddin, M. J., Zaini, M. A. A. 2017b. Dielectric properties of sodium hydroxide-impregnated and activated cempedak peel samples at microwave frequencies. Chem. Eng. Trans. 56, 931-936.

Alias, N., Zaini, M. A. A. 2015. On the view of dielectric properties in microwave-assisted activated carbon preparation. Asia-Pac. J. Chem. Eng. 10, 953-960.

Alias, N., Zaini, M. A. A., Kamaruddin, M. J., You, K. Y. 2017a. Dielectric properties of potassium carbonate-impregnated cempedak peel for microwave-assisted activation. Asia-Pac. J. Chem. Eng. 12, 173-181.

Foo, K. Y., Hameed, B. H. 2011a. Utilization of rice husks as a feedstock for preparation of activated carbon by microwave induced $\mathrm{KOH}$ and $\mathrm{K}_{2} \mathrm{CO}_{3}$ activation. Bioresour. Technol. 102, 9814-9817.

Foo, K. Y., Hameed, B.H. 2011b. Preparation and characterization of activated carbon from sunflower seed oil residue via microwave assisted $\mathrm{K}_{2} \mathrm{CO}_{3}$ activation. Bioresour. Technol. 102, 9794-9799.

Foo, K. Y., Hameed, B. H. 2012a. Preparation of activated carbon by microwave heating of langsat (Lansium domesticum) empty fruit bunch waste. Bioresour. Technol. 116, 522-525.

Foo, K. Y., Hameed, B. H. 2012b. Porous structure and adsorptive properties of pineapple peel based activated carbons prepared via microwave assisted $\mathrm{KOH}$ and $\mathrm{K}_{2} \mathrm{CO}_{3}$ activation. Micropor. Mesopor. Mat. 148, 191-195.

Foo, K. Y., Hameed, B. H. 2012c. Textural porosity, surface chemistry and adsorptive properties of durian shell derived activated carbon prepared by microwave assisted $\mathrm{NaOH}$ activation. Chem. Eng. J. 187, 53-62.

Hesas, R. H., Daud, W. M. A. W., Sahu, J. N., Arami-Niya, A. 2013. The effects of a microwave heating method on the production of activated carbon from agricultural waste: A review. J. Anal. Appl. Pyrol. 100, 1-11.

Hidayu, A. R., Mohamad, N. F., Matali, S., Sharifah, A. S. A. K. 2013 Characterization of activated carbon prepared from oil palm empty fruit bunch using BET and FT-IR techniques. Procedia Eng. 68, 379-384.

Mahmoudi, K., Hamdi, N., Srasra, E. 2014. Preparation and characterization of activated carbon from date pits chemical activation with zinc chloride for methyl orange adsorption. J. Mat. Environ. Sci. 5, 1758-1769.

Mohd.-Nasir, N. H., Zaini, M. A. A., Mohd.-Setapar, S.H., Hassan, H. 2015. Removal of methylene blue and copper(II) by oil palm empty fruit bunch sorbents. J. Tek. Sci. Eng. 74, 107-110.
Motasemi, F., Afzal, M. T., Salema, A. A., Mouris, J., Hutcheon, R. M. 2014. Microwave dielectric characterization of switchgrass for bioenergy and biofuel. Fuel 124, 151-157.

Njoku, V. O., Islam, M. A., Asif, M., Hameed, B. H. 2015. Adsorption of 2,4dichlorophenoxyacetic acid by mesoporous activated carbon prepared from $\mathrm{H}_{3} \mathrm{PO}_{4}$-activated langsat empty fruit bunch. J. Environ. Manage. 154, 138144.

Omar, R., Idris, A., Yunus, R., Khalid, K., Isma, M. I. A. 2011. Characterization of empty fruit bunch for microwave-assisted pyrolysis. Fuel 90, 1536-1544.

Sait, H. H., Salema, A. A. 2015. Microwave dielectric characterization of Saudi Arabian date palm biomass during pyrolysis and at industrial frequencies. Fuel 161, 239-247.

Salema, A. A., Yeow, Y. K., Ishaque, K., Ani, F. N., Afzal, M. T., Hassan, A. 2013. Dielectric properties and microwave heating of oil palm biomass and biochar. Ind. Crop. Prod. 50, 366-374.

Saygili, H., Guzel, F., Onal, Y. 2015. Conversion of grape industrial processing waste to activated carbon sorbent and its performance in cationic and anionic dyes adsorption. J. Cleaner Prod. 93, 84-93.

Shu-Hui, T., Zaini, M. A. A. 2015. Potassium hydroxide activation of activated carbon: A commentary. Carbon Lett. 16, 275-280.

Sosa-Morales, M. E., Valerio-Junco, L., Lopes-Malo, A., Garcia, H. S. 2010. Dielectric properties of foods: Reported data in the 21 st century and their potential applications. LWT Food Sci Tech. 43, 1169-1179.

Zaini, M. A. A., Aini, N. M. N., Kamaruddin, M. J., Yeow, Y. K., Setapar, S. H. M. 2015a. Dielectric properties of potassium hydroxide-treated palm kernel shell for microwave-assisted adsorbent preparation. J. Tek. Sci. Eng. 74, 13-18.

Zaini, M. A. A., Alias, N., Yunus, M. A. C. 2016. Bio-polishing sludge adsorbents for dye removal. Polish J. Chem. Tech. 18, 15-21.

Zaini, M. A. A., Amano, Y., Machida, M. 2010. Adsorption of heavy metals onto activated carbons derived from polyacrylonitrile fiber. J. Hazard. Mater. 180, 552-560.

Zaini, M. A. A., Chai-Li, L. W., Kamaruddin, M. J., Mohd.-Setapar, S. H., Che-Yunus, M. A. 2014a. Irradiated water-activated waste tyre powder for decolourization of reactive Orange 16. J. Tek. Sci. Eng. 68, 95-100.

Zaini, M. A. A., Chiew-Ngiik, T., Kamaruddin, M. J., Mohd.-Setapar, S. H., Che-Yunus, M. A. 2014b. Zinc chloride-activated waste carbon powder for decolourization of methylene blue. J. Tek. Sci. Eng. 67, 37-44.

Zaini, M. A. A., Kamaruddin, M. J. 2013. Critical issues in microwave-assisted activated carbon preparation. J. Anal. Appl. Pyrol. 101, 238-241.

Zaini, M. A. A., Kamaruddin, M. J., Mohd-Setapar, S. H. 2015c. Preparation of activated carbons by microwave-assisted activation: A critical review. In: State of the Art Processing. Mohd-Setapar, S. H., Yian, L. N. (Eds.), Penerbit UTM Press, Johor Bahru, 1-26.

Zaini, M. A. A., Meng, T. W., Kamaruddin, M. J., Setapar, S. H. M., Yunus, M. A. C. 2014c. Microwave-induced zinc chloride activated palm kernel shell for dye removal. Sains Malaysiana 43, 1421-1428.

Zaini, M. A. A., Mohd-Setapar, S. H., Kamaruddin, M. J., Yunus, M. A. C. 2013. In-depth studies of cattle-manure-compost activated carbons for Cu(II) ions removal. In: Agricultural Research Updates Vol. 6. Gorawala, P., Mandhatri, S. (Eds.), Nova Science Publishers, Inc., New York, 247-265.

Zaini, M. A. A., Okayama, R., Machida, M. 2009. Adsorption of aqueous metal ions on cattle-manure-compost based activated carbons. J. Hazard. Mater. 170, 1119-1124.

Zaini, M. A. A., Sabri, N. Z. M., Kamarudin, M. J., Yeow, Y. K. 2015 b. Temperature and composition dependent of dielectric properties of zinc chloride-palm kernel shell mixtures at microwave frequencies. Int. J. Mater. Sci. Eng. 3, 301-309.

Zaini, M. A. A., Shaid, M.S.M. 2016. Metal-chloride-activated empty fruitbunch carbons for Rhodamine B removal. Hung. J. Ind. Chem. 44, 129-133. 